\title{
Functional Dyspepsia: A Narrative Review With a Focus on Sex-Gender Differences
}

\author{
Young Sun Kim ${ }^{1}$ and Nayoung Kim ${ }^{2,3 *}$ \\ ${ }^{I}$ Department of Internal Medicine, Healthcare Research Institute, Seoul National University Hospital Healthcare System Gangnam Center, Seoul, \\ Korea; ${ }^{2}$ Seoul National University Bundang Hospital, Seongnam, Gyeonggi-do, Korea; and ${ }^{3}$ Department of Internal Medicine and Liver Research \\ Institute, Seoul National University College of Medicine, Seoul, Korea
}

Functional dyspepsia (FD) is among the most common gastrointestinal disorders affecting quality of life (QoL). As it frequently occurs in women than in men the comparison of various aspects including prevalence, clinical manifestations, and QoL in FD between women and men is very important for understanding the disease distribution and burden, evaluating treatment options, developing new drugs, and allocating medical resources. However, little is known about sex or gender differences among patients with FD. In spite of limited studies, consistent points are that FD occurs more often in women than in men and there are several symptom differences between men and women with FD. In addition, women with FD tend to have lower QoL than men with FD. Similarly, the pathophysiology of FD likely to vary depending on gender. Furthermore, a sex-gender-oriented approach in healthcare system could enhance understanding heterogeneous patients suffering from FD. Due to the sex-gender differences in physiological and psychological factors, treatment strategies should differ between women and men with FD. In conclusion, an individualized and multicomponent approach that considers sex and gender issues might improve FD treatment and improve patient Qol, especially for women.

(J Neurogastroenterol Motil 2020;26:322-334)

Key Words

Dyspepsia; Gender; Sex

\section{Introduction}

Functional dyspepsia (FD), among the most common gastrointestinal (GI) disorders, is characterized by early satiation, postprandial fullness, epigastric pain, or epigastric burning in the absence of an organic or metabolic disease. ${ }^{1} \mathrm{FD}$ is not a life-threatening serious illness, but its symptoms could persist; rather, they limit one's social life and reduces their quality of life $(\mathrm{QoL}){ }^{2}$ In addition, FD constitutes a serious disease burden worldwide because of its high prevalence. $^{2}$

There has been evidence for sex and gender-related differences in functional gastrointestinal disorders (FGID), particularly irritable bowel syndrome (IBS) $)^{3,4}$ and gastroesophageal reflux disease (GERD). ${ }^{5,6}$ Sex means a human's biological status based on their reproductive systems and functions assigned by chromosomal type. ${ }^{7}$ Gender means manners, feelings, and behaviors in a given culture associated with a person's sex stereotypes. ${ }^{7}$ Gender determines access to health care, help-seeking behavior and individual use of the health care system. ${ }^{7}$ Thus for the effective treatment of FGID

Received: February 12, 2020 Revised: April 11, 2020 Accepted: May 6, 2020

() This is an Open Access article distributed under the terms of the Creative Commons Attribution Non-Commercial License (http://creativecommons. org/licenses/by-nc/4.0) which permits unrestricted non-commercial use, distribution, and reproduction in any medium, provided the original work is properly cited.

${ }^{*}$ Correspondence: Nayoung Kim, MD, PhD Department of Internal Medicine, Seoul National University Bundang Hospital, 82, Gumi-ro 173 beon-gil, Bundang-gu, Seongnam, Gyeonggi-do 13620, Korea

Tel: +82-31-787-7008, Fax: +82-31-787-4051, E-mail: nayoungkim49@empas.com 
clinicians should approach in the background of gender as well as sex. For the IBS and GERD there are several papers regarding sex and gender difference. ${ }^{3-6}$ However, little is known about gender differences among patients with FD. Furthermore, systematic review articles have not been published, except in $2006 .{ }^{8}$ Recently, sex and gender medicine has been defined as the practice of medicine based on the understanding that biology and social roles are important in men and women for prevention, screening, diagnosis, and treatment. ${ }^{9}$ Consequently, a comparison of various aspects including prevalence, clinical manifestations, and $\mathrm{QoL}$ in FD between women and men is very important for understanding the disease distribution and burden, evaluating treatment options, developing new drugs, and allocating medical resources. ${ }^{10}$ From this background, this review tries to address sex and gender differences in the epidemiology, pathophysiology, and clinical presentation of FD based on valuable studies in the recent literature, and discuss the clinical application and future prospects of these differences.

\section{Methodology}

We searched the PubMed using the terms "functional dyspepsia”, "dyspepsia” or "non-ulcer dyspepsia”, "sex" or "gender", “epidemiology" or "prevalence", "pathophysiology", "sex hormone", "symptoms", and "treatment" or "therapy". All searches were completed by April 30, 2020. Every retrieved abstract was reviewed to investigate whether the results included a sex or gender analysis and whether original data were presented. Abstracts that fulfilled these criteria were included in the next level of review of study design, clinical variables, and population. The search was extended by us- ing the references of selected recent articles and systematic reviews or meta-analysis.

\section{Epidemiology}

Large population-based studies have reported an FD prevalence of $10-30 \%$ worldwide. ${ }^{2}$ However, the reported prevalence of FD varies considerably depending on the diagnostic criteria, geographic area in which the population is based, gender, and age. ${ }^{11}$ To meet these criteria for FD in referral populations, upper GI endoscopy must be performed to exclude organic disease. ${ }^{11}$ In population-based studies on the other hand, where organic disease is rare, the implicit assumption is that the majority of subjects meeting the Rome criteria will have FD. ${ }^{2}$ Patients with symptoms of dyspepsia but did not undergo any investigations such as upper GI endoscopy and are not categorized as functional or organic in etiology are classified as having uninvestigated dyspepsia (UD). ${ }^{2} \mathrm{Al}-$ though an accurate diagnosis of FD was not possible in the majority of population-based studies for practical reasons, several studies have investigated community subjects with gastroduodenoscopy. ${ }^{12-15}$ Endoscopy-based studies conducted among adults in the community have been diagnosed with FD between $70.0 \%$ and $80.0 \%$ of people with UD. ${ }^{16}$

A systematic review by the Rome Working Team summarized the available prevalence data for dyspepsia in men and women but reported that the prevalence is heterogeneous. ${ }^{8}$ To the best of our knowledge, only 4 studies have been conducted for general population with performing endoscopy prior to diagnosis of $\mathrm{FD} .{ }^{17-20}$ In the study, women-to-men ratio was 1.4-2.7:1. Studies from large scaled

Table. Summary of Studies Showing Gender Distribution of Patients With Functional Dyspepsia

\begin{tabular}{|c|c|c|c|c|c|c|c|}
\hline Study & Country & $\begin{array}{c}\text { No. of } \\
\text { subjects }\end{array}$ & Setting & Definition & $\mathrm{FD}(\%)$ & Women:Men & $\begin{array}{l}\text { Investigated } \\
\text { population (\%) }\end{array}$ \\
\hline Aro et al, ${ }^{17} 2009$ & Sweden & 1001 & Population based & Rome III & 15.7 & $2.7: 1$ & 100.0 (endoscopy) \\
\hline Zagari et al, ${ }^{18} 2010$ & Italy & 1033 & Population based & Rome II & 28.0 & $1.4: 1$ & 100.0 (endoscopy) \\
\hline Zhao et al, ${ }^{19} 2010$ & China & 16078 & Population based & Rome II & 2.4 & $1.4: 1$ & 6.3 (endoscopy) \\
\hline Matsuzaki et al, ${ }^{20} 2012$ & Japan & 8039 & Population based & Rome III & 7.0 & $1.5: 1$ & 100.0 (upper GI) \\
\hline Lu et al, ${ }^{21} 2005$ & Taiwan & 2018 & $\begin{array}{l}\text { Single health } \\
\text { check-up center }\end{array}$ & $\begin{array}{l}\text { Rome I } \\
\text { Rome II }\end{array}$ & $\begin{array}{l}23.8 \\
11.8\end{array}$ & $\begin{array}{l}1: 1.1 \\
1.3: 1\end{array}$ & 100.0 (endoscopy) \\
\hline Kim et al, ${ }^{13} 2014$ & Korea & 3399 & $\begin{array}{l}7 \text { health check-up } \\
\text { centers }\end{array}$ & Rome III & 20.4 & $1.4: 1$ & 100.0 (endoscopy) \\
\hline Kim et al, 2018 & Korea & 1714 & $\begin{array}{l}9 \text { health check-up } \\
\text { centers }\end{array}$ & Rome III & 10.3 & $1.8: 1$ & 100.0 (endoscopy) \\
\hline
\end{tabular}

FD, functional dyspepsia; GI, gastrointestinal.

Study include population based study and health check-up population applying Rome criteria and excluded organic disease. 
health check-up populations showed similar results (Table). ${ }^{13,21,22}$

A meta-analysis by Ford et $\mathrm{al}^{23}$ for UD also showed a slightly higher prevalence in women than in men $(25.3 \%$ vs $21.9 \%)$ with significant interstudy heterogeneity. In terms of geographic area, North America and some countries in Southern Europe, Northern Europe, Southeast Asia, and the Middle East showed more dyspepsia in women than men, but the same results were not seen in South America, Central America, Australasia, or Africa (Fig. 1), which was very similar to those of IBS. ${ }^{24}$ However, recently Sperber et $\mathrm{al}^{25}$ confirmed a predominance in women, even in those areas. In addition, a recent population based large-scale study of patients with Rome IV criteria using online questionnaires in the United States (US), the United Kingdom, and Canada, women at all ages showed a significantly higher prevalence of FD than men, except for those older than 65 years (Fig. 2). ${ }^{26}$ A population-based cohort study from the National Registry of Iceland demonstrated that significantly more women than men reported FD at a 10 -year followup. $^{27}$

Investigating factors associated with $\mathrm{FD}$ is important because it can reduce unnecessary treatment and reduce the economic costs incurred by FD patients. ${ }^{13}$ Several studies suggested that female sex, a low body mass index (BMI), old age, Helicobacter pylori infection, smoking, use of aspirin or NSAIDs, and low education level are risk factors for $\mathrm{FD} \cdot{ }^{14,15,23,28}$ However, risk factors associated with FD have differed slightly among studies and according to sex.

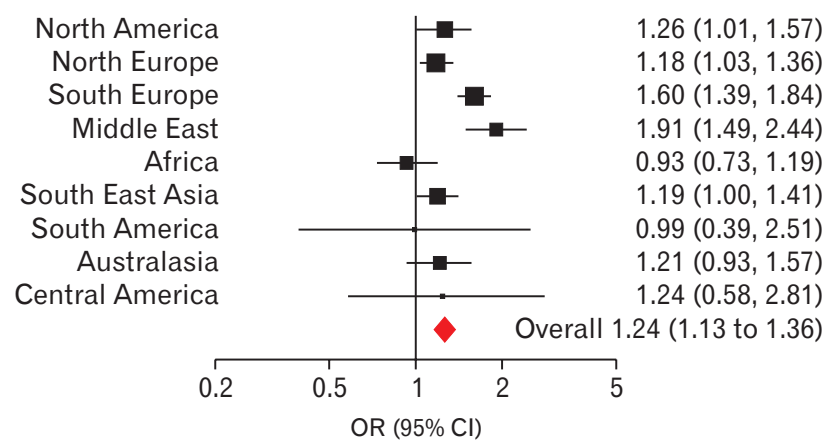

Figure 1. Odds ratio (OR) for uninvestigated dyspepsia in women versus men according to geographical location. The Overall OR for dyspepsia in women compared with men was 1.24 (95\% confidence interval $[\mathrm{CI}], 1.13$ to 1.36 ), with significant heterogeneity between studies (I2 $=91.9 \%, P<0.001)$, but no evidence of funnel plot asymmetry (Egger test, $P=0.860$ ). Data were pooled using a random effects model to give a more conservative estimate of the prevalence of dyspepsia and the odds of dyspepsia in these various groups. Evidence of publication bias was assessed for, by applying Egger's test to funnel plots of ORs, where a sufficient number of studies were available. Reprinted from Ford et $\mathrm{al}^{23}$ with permission.
For example, in a study performed in health check-up population, female sex and education below college level were risk factors for FD. ${ }^{13}$ Especially, education below college level was associated with FD in men, while female sex was related with patients over the age of 60 , suggesting that researchers should pay more attention to this age group. ${ }^{13}$

An abuse history is more common in women with $\mathrm{FD}^{29,30}$ and early childhood is a critical period for the development of certain brain circuits that control stress and nociception. ${ }^{29}$ Forty-two percent of FD patients to whom Rome II criteria were applied had experienced sexual and physical abuse in childhood or adulthood. ${ }^{31}$ Furthermore a childhood abuse history correlated with the development of FD and the severity of dyspepsia was significantly greater in patients with a history of abuse..$^{29}$ Moreover, an abuse history and somatization were related with delayed gastric emptying. ${ }^{32}$ Therefore, it is important to assess patients with FD for a past history of abuse in especially in case of women.

\section{Symptoms}

Some epidemiological studies have reported a male preponderance of "reflux-like" and "ulcer-like" dyspepsia and a female preponderance of "dysmotility-like dyspepsia". ${ }^{33-38}$ For instance the Digital/International Gastroenterology Surveillance Study showed that women were more likely to have dysmotility-like symptoms

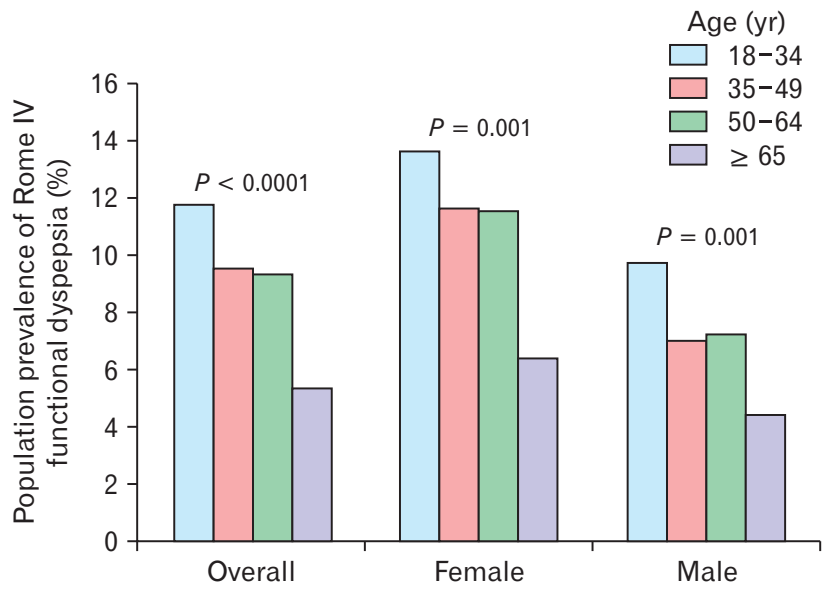

Figure 2. Prevalence of functional dyspepsia (FD) according to sex and age group. The prevalence of FD was significantly higher between the ages of 18 years and 34 years than in the age groups 35-49 years and 50-64 years, with the lowest prevalence of FD seen in individuals older than 65 years. This pattern was seen across both sexes. Women had a significantly greater prevalence of FD than their men counterparts across all age groups, except for in those older than 65 years. Reprinted from Aziz et $\mathrm{al}^{26}$ with permission. 
than men. ${ }^{36}$ Whereas, women with FD complained more of upper abdominal pain than men with FD, which correlated with female anxiety scores. In particular, women who underwent gynecological surgery had more severe abdominal symptoms than women who did not. ${ }^{10}$ In addition, women are more likely to continue to report FD symptoms over time. ${ }^{29}$ Women tend to continually complain of symptoms or experience greater suffering than men and are more likely to have associated psychosocial factors. ${ }^{39,40}$ However, other studies have found no difference in the prevalence of dyspepsia subgroups between men and women. ${ }^{10,29,41-43}$

\section{Overlap Syndrome}

The mechanism by which FD coexists with other FGIDs is not yet fully known, but it may be due to similar common pathophysiological factors such as visceral hypersensitivity, altered GI motility, dysfunction of the brain and gut interaction, and psychological comorbidities. ${ }^{23,39}$ FGIDs such as GERD, FD, and IBS sometimes overlap. ${ }^{27,44-48}$ Several studies found that FGIDs more commonly overlap in women than in men. ${ }^{47,48}$ For instance, patients with overlapping FD and GERD were more likely to be young and female. ${ }^{47}$ In addition, a Chinese study showed that overlapping IBS and FD was reportedly associated with female sex, divorced or widowed versus married status, abdominal distension, decreased bowel movements, and mixed IBS. ${ }^{48}$ It is well known that overlap among these FGIDs can impair health-related QoL, ${ }^{47,49,50}$ and the negative effect on QoL was greater in subjects with the overlap of 3 conditions (FD, IBS, and GERD) in both men and women irrespective of age. ${ }^{51}$ Furthermore, a study regarding overlap of FD and IBS showed no significant gender difference for overlap versus non-overlap patients. ${ }^{6}$ Further studies are needed to address this issue.

\section{Quality of Life}

FD patients present more impaired QoL than controls, especially in terms of social and environmental aspects, suggesting that more aggressive interventions are needed to improve FD symptoms. ${ }^{10,52}$ However, studies on factors associated with health related QoL in patients with FD are rare. Several studies showed that women with FD tend to be more depressed and anxious and have lower QoL than men with FD. ${ }^{10,52,53}$ For example, a populationbased case-control study from Sweden ${ }^{53}$ showed that women with FD suffered significantly poorer QoL including physical function, limited physical role, physical pain, and overall health awareness compared to sex-matched controls. In another study, women with FD scored significantly lower in overall $\mathrm{QoL}$ and general health and physical domains than men with $\mathrm{FD} .{ }^{10}$ In addition, women with FD had higher mean hospital anxiety and depression scale (HADS) scores than men with FD. Epigastric pain severity correlated with HADS anxiety scores only in women with FD. ${ }^{10}$ Therefore, adjusting these aspects is important in relieving symptoms of FD. A recent cross-sectional study performed in Asia showed that factors associated with a low QoL in FD patients included female sex, anxiety, depression, old age, severe symptoms, and low educational level. ${ }^{52}$

\section{Health Care-seeking Behavior and Socioeconomic Impact}

FD patients incur significant health costs, which impose an economic burden on the health care system. ${ }^{53}$ Information on healthcare seeking behavior will help the development of healthcare policies and management of FD. Several studies have reported higher consultation rates by women than by men in FD patients. ${ }^{54,55}$ Psychosocial factors such as somatization and physical or sexual abuse are associated with increased health care use. ${ }^{56}$ On the other hand, a population study using Rome I criteria showed that health care seeking for dyspepsia was similar in men and women. ${ }^{57}$ In the study, symptom severity, frequency and pattern (eg, ulcer-like and dysmotility-like) were important independent factors in determining health care seeking. ${ }^{57}$ Another study from Taiwan using the Rome I and Rome II criteria for health check-up populations showed no gender difference in terms of physician-consultation behavior, and school/work absenteeism. ${ }^{21}$ Probably medical consultation rates vary across different regions or countries for the variety of medical setting and levels of satisfaction with the physician-patient relationship. In a community-based survey enrolling mainly Muslims in East Malaysia, married women were more likely to have FD and psychosocial symptoms than married men, but consultation rates were lower. ${ }^{58}$ However, until now almost no population-based large scaled study has evaluated gender differences in health-seeking behaviors using the Rome III or IV criteria in FD. So, further studies are needed.

FD impairs work ability and incurs high medical costs worldwide. ${ }^{53}$ However, there is a paucity of data on gender difference in the economic impact of FD. In a study based on FD patients attending a tertiary care center in the US, it estimated the direct and indirect costs of FD at US $\$ 18.4$ billion for the entire US population or US $\$ 80000$ per 1000 US population for the 2009 financial year. ${ }^{53}$ No cost differences were identified between men and women 
in the study. However, the study did not include gender-specific analysis for indirect costs due to missing work and lost productivity.

\section{Pathophysiology}

Various complex mechanisms have been proposed for the pathogenesis of FD, including altered gastric motility, visceral hypersensitivity, brain-gut interactions, low-grade mucosal inflammation, $H$. pylori infection, and genetic or social and psychological factors, but the etiology and optimal treatment of FD remain unclear. ${ }^{12,39,59}$ Moreover, the underlying pathogenesis for the gender difference in $\mathrm{FD}$ has not been investigated in detail.

\section{Sex Hormones}

Sex hormones are the most important factor biologically characterizing men and women. Estrogens might play a role in the control of motor and sensory functions of the GI tract through direct or indirect action on immune, endocrine, and neuronal pathways as well as interactions with the gut microbiota. ${ }^{60}$ However, most research has been focused on the motility aspect and female sex hormones cause change of gastric motility. ${ }^{10}$ That is, gastric emptying is delayed in the luteal phase versus the follicular phase ${ }^{61}$ and delayed in premenopausal women versus men. ${ }^{32,61,62} \mathrm{Chen} \mathrm{et} \mathrm{al}^{63}$ demonstrated that estradiol (E2) and a mixture of E2 and progesterone inhibit gastric emptying, whereas testosterone did not.

Furthermore, women's visceral nociception can be affected by periodic changes in the female sex hormones. ${ }^{64,65}$ Estrogen interacts with neurotransmitters to modulate pain response in pain recognition pathways. ${ }^{66}$ Estrogen also affects women's emotions and moods. When estrogen levels are interrupted or fluctuate in women after menopause, oophorectomy, or childbirth or during menstruation, woman experience severe mood swings including changes in premenstrual mood, postpartum depression, and postmenopausal depression. ${ }^{67-69}$ Based on these findings, female sex hormones might affect visceral pain and gastric motility, supporting female sex as a risk factor of $\mathrm{FD} .^{13}$

\section{Psychological Distress}

Psychological disorders are common in FGID; in particular, anxiety and depression are common in patients with FD despite conflicting reports in some cases. ${ }^{69-72}$ There are differences between men and women in response to stress hormones. Women are more vulnerable to stress-related disorders due to sex differences in the corticotropin-releasing factor (CRF) and locus coeruleusnorepinephrine system that increase their sensitivity to stress. ${ }^{73}$ In men, when CRF is excessively secreted, internalization of the CRF receptor occurs and the response to the $\mathrm{CRF}$ is weakened. On the other hand, in women, internalization of the CRF receptor does not occur and the response to CRF hypersecretion is transmitted as it is. ${ }^{73}$ In addition, estrogen attaches to the estrogen alpha receptors in the hypothalamus and interferes with the negative feedback of cortisol, which also affects stress control in women. Thus, when faced with extreme or prolonged stress conditions, women are more vulnerable to stress because the CRF-mediated endocrine system and arousal system are likely to result in poor control. ${ }^{73}$ Somatization is an important determinant of symptom severity in $\mathrm{FD}^{74}$ Moreover, sex-based differences in CRF function have important implications for the development of therapeutic drugs. Because CFR hypersecretion is more common in stressed women, $\mathrm{CRF}$ antagonists may be more effective in women than in men. ${ }^{73}$

\section{Altered Functional Connectivity of the Amygdala and Sex-based Differences}

Several researchers have found significant functional and anatomical alterations in multiple brain regions that are related to the default mode network and salience network in patients with $\mathrm{FD}{ }^{74-77}$ In particular, the amygdala is considered the key part in the pathogenesis of $\mathrm{FD}$ because of its wide involvement in processing interoceptive signals of satiety and fullness, food intake, emotional control, and endogenous pain inhibition. ${ }^{74}$ Zeng et $\mathrm{al}^{74}$ demonstrated that women with FD had more severe dysfunction of cognitive-affective processing in multiple networks. Patients with FD demonstrated altered resting-state functional connectivity $(\mathrm{rsFC})$ in the basolateral amygdala (BLA) and centromedial amygdala subregions compared with healthy controls, while women with FD revealed increased BLA rsFC with the insula and decreased BLA rsFC with the medial prefrontal cortex and dorsal lateral prefrontal cortex compared with men with FD and healthy women. ${ }^{74}$ Taken together it indicates that the visceral afferents are amplified and negative emotion is enhanced compared with men with FD and healthy women. ${ }^{74}$ These results aid in the understanding of why women are more sensitive to pain than men and report GI pain/discomfort more often. ${ }^{68}$

\section{Gastroduodenal Motor and Sensory Dysfunction: Gastric Emptying}

GI sensory motor dysfunction such as hypersensitivity to gastric distension, and delayed gastric emptying are common in patients with FD and have been suggested to contribute to the pathogenesis of symptoms of $\mathrm{FD}^{78,79} \mathrm{~A}$ study investigating the gender differences of gastric emptying using a ${ }^{13} \mathrm{C}$-acetate breath test demonstrated 
that gastric emptying was delayed in healthy women versus healthy men. ${ }^{80}$ In men with FD, mean BMI was lower in the group with delayed gastric emptying; in women with FD, the delayed gastric emptying group complained of more severe reflux symptoms than the group without delayed emptying. ${ }^{80}$ In addition, GERD questionnaire scores were higher in the delayed gastric emptying group than in the group without delayed emptying among women with FD implying that delayed gastric emptying triggered GERD in women with $\mathrm{FD}^{80}$

Studies using a beverage test at administer nutrient or water drinks at a constant rate up to the level of discomfort found that women have a lower tolerance than men. ${ }^{81,82}$ However, the reasons for sex differences in the postprandial response are unclear. A study measuring the sensations induced by gastric distension showed that the same pressure and volume induced more extreme perceptions in women, suggesting that a woman's stomach is more sensitive, and perceives and tolerates smaller intraluminal loads than in men. ${ }^{83}$ Studies using a gastric barostat demonstrated that the gastric accommodation reflex is more prolonged in women than in men, ${ }^{84}$ which might be associated with more definite vagal tone. ${ }^{83}$

\section{Ghrelin}

Ghrelin is an important digestive hormone that controls appetite and regulate gastric motility. ${ }^{85-87}$ Acyl ghrelin reduction is associated with delayed gastric emptying ${ }^{88}$ leading to vomiting or postprandial fullness. ${ }^{34,89}$ Fasting plasma acylated ghrelin levels were not significantly different between healthy controls and patients with FD, whereas ghrelin levels were related with subjective symptom scores of FD in women. ${ }^{59}$ In contrast, the difference in plasma acyl ghrelin between FD patients (postprandial distress syndrome [PDS] subtype) and controls was statistically significant in men but not in women. ${ }^{10}$ Similarly, elevated level of pain-related genes (nerve growth factor, glial cell line-derived neurotrophic factor, and transient receptor potential vanilloid-1 [TRPV1]) mRNA expressions in the FD group was important in men but anxiety and depression were important in women. ${ }^{10}$

\section{Familial Aggregation and Genes}

Although data are limited, the clustering of patients with FD in families suggests the role of genetic factors in the pathogenesis of FD. ${ }^{39,90}$ Several studies found susceptible genes related with FD, but the results are heterogenous. ${ }^{91,92}$ A Japanese study demonstrated that the COX-1-1676T allele was significantly related with an increased risk for the epigastric pain syndrome (EPS) subgroup of FD in women. ${ }^{92}$ A recent meta-analysis did not demonstrate that only minor allele (T) of GNB3 $825 \mathrm{C}>\mathrm{T}$ was related to increased susceptibility to the EPS subtype of FD. ${ }^{92}$ However, studies on whether the related genes differ between men and women were very limited in patients with FD. Further large-scale research including sex analysis with an adequate validation method is needed to clarify the role of genetic factors in $\mathrm{FD}$.

\section{Microbiota}

The gut microbiota, immune cells, enteroendocrine cells, and enteric nervous system are known to have complex interactions, and the disruption or alteration of gut microbiota due to unclear mechanisms plays an important role in the pathogenesis of FD. ${ }^{93}$ Flak et $\mathrm{al}^{94}$ proposed a concept called "microgenderome", the bidirectional interaction between microbiota and sex hormones. As sex differences in gut microbiota do not appear until puberty, the role of sex hormones in shaping the gut microbiota composition is supported. ${ }^{95}$ Moreover, women's gut microbiota diverges before and after menopause, with the gut microbiota of postmenopausal women becoming very similar to that of men. ${ }^{96} \mathrm{~A}$ study evaluated the relation of age, sex, and gut bacterial alpha diversity in 3 large cohorts of adults from 4 geographical regions demonstrated sex-dependent differences in the US, the United Kingdom, and Colombian cohorts. ${ }^{97}$ In addition, a recent study showed that gut microbiome diversity was associated with the levels of testosterone in men and E2 in women. ${ }^{98}$ Interestingly, gut microbiota can affect the estrogen level by deconjugating the conjugated estrogen molecules excreted through the bile and reabsorbing it through the enterohepatic circulation. ${ }^{99}$ There have been human studies investigating the gut microbiome in patients with FD. ${ }^{100-102}$ In addition, randomized controlled trials of probiotics and selective antibiotics such as rifaximin showed improvement in symptoms and the microbiome of patients with $\mathrm{FD},{ }^{100}$ and the bacterial composition and structure of gastric fluid in patients with FD differed from that of healthy controls. ${ }^{102}$ Since studies are very limited on how sex differences in the gut microbiota affect the pathogenesis of FD, further studies are needed to elucidate this issue.

\section{Low-grade Inflammation and Tight Junction Proteins}

It was recently demonstrated that low-grade inflammation in patients with FD increases duodenal mucosal permeability, ${ }^{103}$ subsequently causing duodenal hypersensitivity to several mediators such as lipids, capsaicin and acids, playing a role in the onset of FD. ${ }^{104}$ Tight junction (TJ) proteins are components of the GI mucosal barrier, and impaired barrier function of the duodenal mucosa 
might be related to $\mathrm{TJ}$ protein expression. Several studies suggested that sex hormones might play a role in the regulation of gut $\mathrm{TJ}{ }^{105,106}$ Our team found significantly higher CLDN2 mRNA expression in the men PDS and men EPS groups than in the male control group, but not in women, indicating that Claudin-2 is involved in FD irrespective of $H$. pylori status, especially in the pathophysiology of men with FD. ${ }^{107}$ However, since very limited studies have investigated the sex differences in $\mathrm{TJ}$ proteins in patients with $\mathrm{FD}$, additional studies are needed to clarify these findings.

\section{Food}

In a recent systematic review, wheat and gluten ingestions were associated with to PDS and EPS of FD, while dietary fats consistently influence PDS. ${ }^{108}$ Naturally occurring food chemicals, fermentable oligosaccharides, disaccharides, monosaccharides, and polyols or other known food intolerances are reported to cause symptoms. ${ }^{108}$ However, because of the lack of high quality dietary evaluations, with few researches using validated methods, conclusions are limited. ${ }^{108}$ Moreover, limited sex differences were analyzed for the association between food and symptoms. A recent crosssectional study investigated relations between dietary glycemic index or glycemic load and uninvestigated chronic dyspepsia showed sex-specific associations between dietary carbohydrate quality and dyspepsia. ${ }^{109}$ That is, higher dietary glycemic index and glycemic load may be risk factors for chronic dyspepsia in men and normalweight subjects but not in women and overweight subjects. ${ }^{109} \mathrm{~A}$ randomized parallel trial comparing the postprandial responses to a delicious and comfortable meal between men and women showed gender differences in the biological responses to having a meal. ${ }^{110}$ Women showed a more postprandial fullness than men. Women's hedonic responses were also more pronounced than those in men. ${ }^{110}$ Women also showed more noticeable effects on vagal tone and a different lipoprotein response than men. ${ }^{110}$ These differences between women and men in biological response to meal ingestion may help explain the gender differences in FD.

\section{Treatment}

Current treatments for FD demonstrate only modest efficacy over placebo, and not all treatments are effective in all cases of $\mathrm{FD} .{ }^{111}$ In addition, pharmacokinetic differences exist between women and men. A recent systematic review ${ }^{112}$ evaluating the effect of gender differences on drug therapy found that women generally have a shorter gastric emptying time, lower gastric $\mathrm{pH}$, lower lean body mass, a higher plasma volume, BMI, body fat, a decreased hepatic clearance, different cytochrome P450 enzyme activity, and different drug metabolic rates than men. These differences can lead to side effects in women, especially those who are pregnant, postmenopausal, or elderly. ${ }^{112}$ Many pharmacological interventions have been tested with various results, and while many clinical trials enrolled more women than men with FD, no studies have specifically investigated sex-gender differences in therapeutic outcomes or compliance with $\mathrm{FD}$ treatment. ${ }^{12}$

\section{Proton Pump Inhibitors}

Proton pump inhibitors (PPIs) are often the first drug of choice for treating FD symptoms, although they are effective in only $7-10 \%$ of FD patients compared to placebo. ${ }^{113}$ There are no gender restrictions for Food and Drug Administration approval of any of the histamine $\mathrm{H}_{2}$ blockers or PPIs. ${ }^{12}$ A study investigated the pattern of dyspepsia evaluation and treatment over 20 years in a population-based cohort and investigated that the management was influenced by dyspepsia subgroup and that men were significantly more likely than women to be treated with PPIs. ${ }^{57}$ In contrast, there was a tendency for women to be more likely than men to be treated with psychological agents. ${ }^{57}$ However, no additional studies have investigated whether there is a gender difference in the use of PPI in patients with $\mathrm{FD}$, requiring further large scaled studies.

\section{Helicobacter pylori Eradication}

Several studies on $H$. pylori-associated FD have investigated changes in the gut environment. ${ }^{114}$ In guidelines on FD made in the Asia-Pacific region, Japan, the US and Canada, H. pylori eradication is strongly recommended as a primary treatment in patients with $H$. pylori-positive dyspepsia. ${ }^{115,116}$ However, there are limited gender analyses of $H$. pylori treatment differences in FD. A prospective multicenter clinical trial performed in Korea showed that successful $H$. pylori eradication was related to symptom improvement. ${ }^{22}$ Considering factors that predict FD symptom response after $H$. pylori eradication, female sex, eradiation failure, and medication for FD during the study period were related with poor $\mathrm{FD}$ response at 1 year on univariate analysis. ${ }^{22}$ The reason why the improvement of FD symptoms after $H$. pylori eradication in women is lower than in men might be related to women complaining of more frequent symptoms, ${ }^{117}$ showing longer gastric emptying. times ${ }^{118}$ and a higher prevalence of psychological co-morbidities than men ${ }^{69,119}$ rather than $H$. pylori-associated inflammation.

A significant elevation of ${ }^{13} \mathrm{C}$-urea breath test (UBT) values among women versus men infected with $H$. pylori was recently reported, suggesting gender differences in the $H$. pylori host interac- 
tion. ${ }^{120}$ A study evaluating the pattern of ${ }^{13} \mathrm{C}-\mathrm{UBT}$ referrals among a large cohort of dyspeptic patients showed that more women were referred for ${ }^{13} \mathrm{C}-\mathrm{UBT}^{121}$ More men showed positive results. The mean test values were significantly higher among women, probably suggesting an increased bacterial load among women and gender related differences in $H$. pylori-host interactions. ${ }^{121}$ Most studies investigating changes in dyspeptic symptoms after successful $H$. pylori eradication in patients with FD included short observational periods; thus, studies with longer observational periods are needed.

\section{Antidepressants}

Antidepressants, both tricyclic antidepressants and selective serotonin (5-HT) reuptake inhibitors (SSRI), are often used to treat abdominal pain of FD. ${ }^{40,113}$ Regarding depression, several studies have reported that the response rates of tricyclic antidepressants and SSRI differed by gender ${ }^{71,122-125}$ For instance, younger females exposed to the SSRI (fluvoxamine) showed greater response than males and older females as well ( $>44$ years old). ${ }^{125}$ Maybe it is related with estrogen that has subsequently been shown to influence 5-HT synthesis, as well as 5-HT receptor binding and activity. Several studies also suggested that women respond better to antidepres- sants such as SSRI than men. ${ }^{126-129}$ However, very limited studies have evaluated gender differences in the use of these drugs specifically for FD. A recent study showed that low-dose antidepressant therapy effectively improved patient symptoms and satisfaction with fewer side effects in refractory FD. ${ }^{123}$ However, sex was not a related factor in the response to antidepressants. ${ }^{123}$ Further studies of gender differences in response to antidepressants for the patients with $\mathrm{FD}$ are required in the future.

\section{Targeting the Microbiome}

A recent small scaled research by Zhong et $\mathrm{al}^{130}$ showed that duodenal bacterial load is directly correlated with symptom severity in $\mathrm{FD}$, suggesting a role of antibiotics for improving the duodenal microbiome in subjects with FD. ${ }^{130,131}$ Rifaximin was shown to change the gut microenvironment with mechanisms of action including the prevention of gut inflammation and reduction of visceral hypersensitivity. ${ }^{130,132} \mathrm{~A}$ recent randomized controlled trial study from China, ${ }^{100}$ which excluded patients with IBS, demonstrated that rifaximin was superior to placebo for the relief of overall dyspeptic symptoms, postprandial fullness/bloating, and belching. In addition, women experienced more remarkable and sustained
Sex-gender differences $\$ \sigma^{\prime \prime}$

Sex hormone

Psychological comorbidities

Central signaling via CRF

Amygdala functional connectivity

Gastric emptying

Ghrelin

Genetics

Gut microbiome

Response to luminal factor (food)

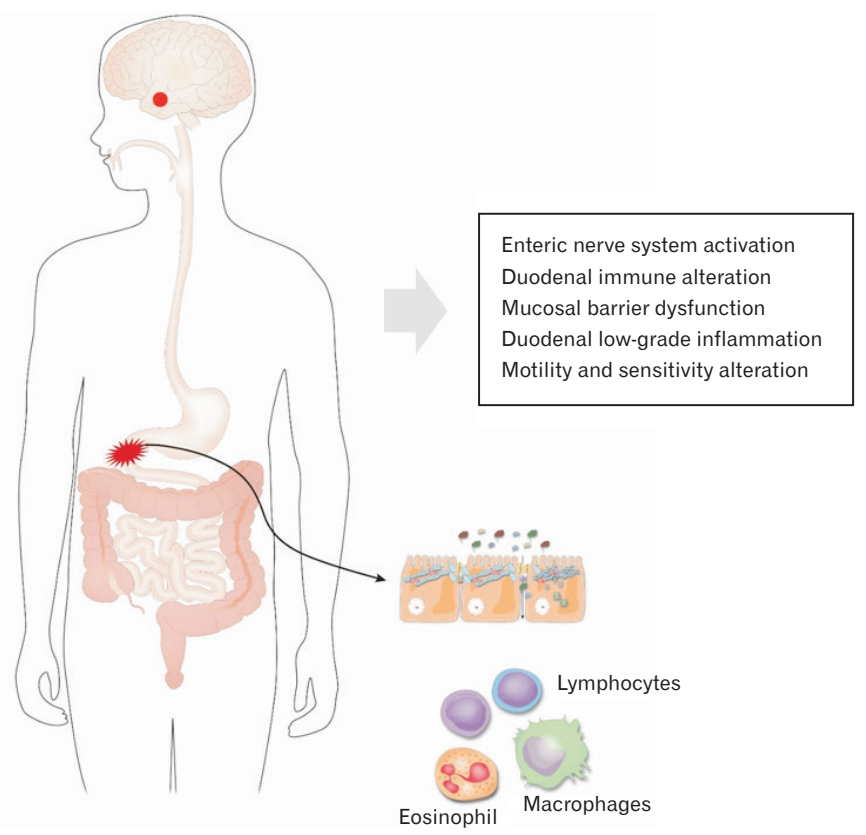

Sex-gender differences

Prevalence

Symptoms

Quality of life

Socioeconomic impact

Management

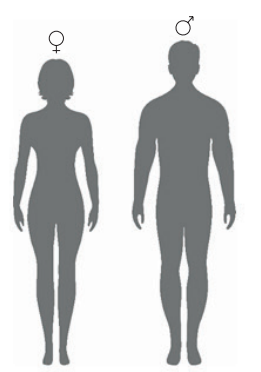

Figure 3. Sex and gender related differences in pathophysiology of functional dyspepsia (FD). Although the detailed investigation is lacking, the underlying pathophysiology of FD likely to vary depending on women and men. That is, although the pathophysiology of FD is complex and heterogeneous, accumulating knowledge indicates that sex and gender difference in sex hormone, psychological distress, central signaling via corticotropin-releasing factor $(\mathrm{CRF})$, altered functional connectivity of amygdala, ghrelin, genetic factor, gut microbiome, and luminal factor such as food might affect enteric nerve system, duodenal immune activation, mucosal barrier function, duodenal low-grade inflammation, or alteration of gut motility and sensitivity, resulting in the difference outcome of FD between women and men. 
improvement in overall dyspeptic symptoms as well as postprandial bloating and belching, but men did not. ${ }^{100}$ However, they did not suggest why there was a gender difference in symptom improvement. Considering probiotics, a recent double-blind randomized controlled trial (RCT) of $H$. pylori-uninfected patients with FD that evaluated the efficacy of Lactobacillus gasseri OLL2716-containing yogurt demonstrated significantly higher elimination rates for the major FD symptoms including PDS-like, but not EPS-like symptoms of L. gasseri OLL2716 group compared to the placebo group. ${ }^{133}$ However, the study did not conduct separate analyses by sex. In addition, the sample size was small. Large-scale studies are warranted to evaluate the gender difference in the efficacy of probiotics for the patients with FD.

\section{Prokinetics}

A recently updated systematic review and meta-analysis of RCTs to support the 2017 joint the American College of Gastroenterology and the Canadian Association of Gastroenterology dyspepsia guidelines showed that prokinetics were effective for the treatment of all FD subtypes $\left(\mathrm{RR}=0.81 ; 95 \% \mathrm{CI}, 0.74-0.89 ; \mathrm{I}^{2}=91 \%\right.$; number needed to treat, 7) regardless of FD subtype or ethnicity. ${ }^{115}$ The review of gender differences in medications for GI problems such as IBS resulted in restrictions of the approval of both alosetron, a $5-\mathrm{HT}_{3}$ receptor antagonist, and tegaserod, a partial $5-\mathrm{HT}_{4}$ receptor agonist. ${ }^{69}$ However, no study has evaluated gender differences in the management of $\mathrm{FD}$ with prokinetics.

\section{Conclusion}

Historically, the terminology of gender was introduced because sex could not explain the difference of males and females. Thus this term is changing over the period of time and area. As a result, our review regarding sex- and gender difference of FD has several limitations. In this review including very recent publications, we found that sex and gender differences related to FD prevalence, pathophysiology, symptoms, and treatment responses showed somewhat mixed results. In spite of limited studies consistent points are FD occurs more often in women than in men and there are several symptom differences between men and women with FD. In addition, women with FD tend to have lower QoL than men with FD. Similarly, the pathophysiology of FD is likely to vary depending on men and women (Fig. 3). That is, anxiety and depression seem to play a relatively bigger role in women than in men and that of ghrelin or TRPV1 is reverse in FD. For treatment, convincing RCTs including comprehensive sex and gender analysis are lacking. Fur- ther studies assessing sex and gender differences in FD are needed to enhance patient care and improve patient QoL.

Financial support: This research was supported by Support Program for Women in Science, Engineering and Technology through the Center for Women In Science, Engineering and Technology (WISET) funded by the Ministry of Science and ICT (No. WISET202003GI01).

\section{Conflicts of interest: None.}

Author contributions: Young Sun Kim: design for contents and drafting the article; and Nayoung Kim: key concept and revision.

\section{References}

1. Tack J, Talley NJ. Functional dyspepsia--Symptoms, definitions and validity of the Rome III criteria. Nat Rev Gastroenterol Hepatol 2013;10:134-141.

2. Mahadeva S, Goh KL. Epidemiology of functional dyspepsia: a global perspective. World J Gastroenterol 2006;12:2661-2666.

3. Chang L, Heitkemper MM. Gender differences in irritable bowel syndrome. Gastroenterology 2002;123:1686-1701.

4. Kim YS, Kim N. Sex-gender differences in irritable bowel syndrome. J Neurogastroenterol Motil 2018;24:544-558.

5. Ford AC, Forman D, Reynolds PD, Cooper BT, Moayyedi P. Ethnicity, gender, and socioeconomic status as risk factors for esophagitis and barrett's esophagus. Am J Epidemiol 2005;162:454-460.

6. Kim YS, Kim N, Kim GH. Sex and gender differences in gastroesophageal reflux disease. J Neurogastroenterol Motil 2016;22:575-588.

7. Annandale E, Hammarström A. Constructing the 'gender-specific body': a critical discourse analysis of publications in the field of genderspecific medicine. Health (London) 2011;15:571-587.

8. Ahlawat SK, Cuddihy MT, Locke GR 3rd. Gender-related differences in dyspepsia: a qualitative systematic review. Gend Med 2006;3:31-42.

9. Jenkins MR, Herrmann A, Tashjian A, et al. Sex and gender in medical education: a national student survey. Biol Sex Differ 2016;7(suppl 1):45.

10. Choi YJ, Park YS, Kim N, et al. Gender differences in ghrelin, nociception genes, psychological factors and quality of life in functional dyspepsia. World J Gastroenterol 2017;23:8053-8061.

11. Stanghellini V, Chan FK, Hasler WL, et al. Gastroduodenal disorders. Gastroenterology 2016;150:1380-1392.

12. Napthali K, Koloski N, Walker MM, Talley NJ. Women and functional dyspepsia. Womens Health (Lond) 2016;12:241-250.

13. Kim SE, Park HK, Kim N, et al. Prevalence and risk factors of functional dyspepsia: a nationwide multicenter prospective study in Korea. J Clin Gastroenterol 2014;48:e12-e18.

14. Kim SE, Park YS, Kim N, et al. Effect of Helicobacter pylori eradication on functional dyspepsia. J Neurogastroenterol Motil 2013;19:233243. 
15. Shaib Y, El-Serag HB. The prevalence and risk factors of functional dyspepsia in a multiethnic population in the United States. Am J Gastroenterol 2004;99:2210-2216.

16. Ford AC, Marwaha A, Lim A, Moayyedi P. What is the prevalence of clinically significant endoscopic findings in subjects with dyspepsia? Systematic review and meta-analysis. Clin Gastroenterol Hepatol 2010;8:830-837,837, e1-e2.

17. Aro P, Talley NJ, Ronkainen J, et al. Anxiety is associated with uninvestigated and fuctional dyspepsia (Rome III criteria) in a Swedish population-based study. Gastroenterology 2009;137:94-100.

18. Zagari RM, Law GR, Fuccio L, et al. Epidemiology of functional dyspepsia and subgroups in the Italian general population: an endoscopic study. Gastroenterology 2010;138:1302-1311.

19. Zhao Y, Zou D, Wang R, et al. Dyspepsia and irritable bowel syndrome in China: a population-based endoscopy study of prevalence and impact. Aliment Pharmacol Ther 2010;32:562-572.

20. Matsuzaki J, Suzuki H, Asakura K, et al. Classification of functional dyspepsia based on concomitant bowel symptoms. Neurogastroenterol Motil 2012;24:325-e164.

21. Lu CL, Lang HC, Chang FY, et al. Prevalence and health/social impacts of functional dyspepsia in Taiwan: a study based on the rome criteria questionnaire survey assisted by endoscopic exclusion among a physical check-up population. Scand J Gastroenterol 2005;40:402-411.

22. Kim SE, Kim N, Lee JY, et al. Prevalence and risk factors of functional dyspepsia in health check-up population: a nationwide multicenter prospective study. J Neurogastroenterol Motil 2018;24:603-613.

23. Ford AC, Marwaha A, Sood R, Moayyedi P. Global prevalence of, and risk factors for, uninvestigated dyspepsia: a meta-analysis. Gut 2015;64:1049-1057.

24. Lovell RM, Ford AC. Effect of gender on prevalence of irritable bowel syndrome in the community: systematic review and meta-analysis. Am J Gastroenterol 2012;10:991-1000.

25. Sperber AD, Dumitrascu D, Fukudo S, et al. The global prevalence of IBS in adults remains elusive due to the heterogeneity of studies: a rome foundation working team literature review. Gut 2017;66:1075-1082.

26. Aziz I, Palsson OS, Törnblom H, Sperber AD, Whitehead WE, Simrén M. Epidemiology, clinical characteristics, and associations for symptom-based Rome IV functional dyspepsia in adults in the USA, Canada, and the UK: a cross-sectional population-based study. Lancet Gastroenterol Hepatol 2018;3:252-262.

27. Olafsdottir LB, Gudjonsson H, Jonsdottir HH, Thjodleifsson B. Natural history of functional dyspepsia: a 10 -year population-based study. Digestion 2010;81:53-61.

28. Campesi I, Romani A, Franconi F. The sex-gender effects in the road to tailored botanicals. Nutrients 2019;11:E1637.

29. Geeraerts B, Van Oudenhove L, Fischler B, et al. Influence of abuse history on gastric sensorimonitor function in functional dyspepsia. Neurogastroenterol Motil 2009;21:33-41.

30. Oshima T, Fukui H, Watari J, Miwa H. Childhood abuse history is associated with the development of dyspepsia: a population-based survey in Japan. J Gastroenterol 2015;50:744-750.

31. Van Oudenhove L, Vandenberghe J, Vos R, Fischler B, Demyttenaere K,
Tack J. Abuse history, depression, and somatization are associated with gastric sensitivity and gastric emptying in functional dyspepsia. Psychosom Med 2011;73:648-655.

32. Hutson WR, Roehrkasse RL, Wald A. Influence of gender and menopause on gastric emptying and motility. Gastroenterol 1989;9:11-17.

33. Drossman DA, Li Z, Andruzzi E, Temple RD, et al. U.S. householder survey of functional gastrointestinal disorders. Prevalence, sociodemography, and health impact. Dig Dis Sci 1993;38:1569-1580.

34. Talley NJ, Zinsmeister AR, Schleck CD, Melton LJ 3rd. Dyspepsia and dyspepsia subgroups: a population-based study. Gastroenterology 1992;102(4 Pt 1):1259-1268.

35. Stanghellini V, Tosetti C, Paternicò A, et al. Predominant symptoms identify different subgroups in functional dyspepsia. Am J Gastroenterol 1999;94:2080-2085.

36. Stanghellini V. Three-month prevalence rates of gastrointestinal symptoms and the influence of demographic factors: results from the Domestic/International Gastroenterology Surveillance Study (DIGEST). Scand J Gastroenterol Suppl 1999;231:20-28.

37. Chang CS, Poon SK, Lien HC, Chen GH. The incidence of reflux esophagitis among the Chinese. Am J Gastroenterol 1997;92:668-671.

38. Johnsen R, Bernersen B, Straume B, Førde OH, Bostad L, Burhol PG. Prevalences of endoscopic and histological findings in subjects with and without dyspepsia. BMJ 1991;302:749-752.

39. Talley NJ. Functional dyspepsia: advances in diagnosis and therapy. Gut Liver 2017;113:349-357.

40. Welén K, Faresjö A, Faresjö T. Functional dyspepsia affects women more than men in daily life: a case-control study in primary care. Gend Med 2008;5:62-73.

41. Agréus L, Svärdsudd K, Nyrén O, Tibblin G. The epidemiology of abdominal symptoms: prevalence and demographic characteristics in a Swedish adult population. A report from the abdominal symptom study. Scand J Gastroenterol 1994;29:102-109.

42. Ruth M, Månsson I, Sandberg N. The prevalence of symptoms suggestive of esophageal disorders. Scand J Gastroenterol 1991;26:73-81.

43. Isolauri J, Laippala P. Prevalence of symptoms suggestive of gastro-oesophageal reflux disease in an adult population. Ann Med 1995;27:6770.

44. de Bortoli N, Tolone S, Frazzoni M, et al. Gastroesophageal reflux disease, functional dyspepsia and irritable bowel syndrome: common overlapping gastrointestinal disorders. Ann Gastroenterol 2018;31:639648.

45. Quigley EM, Lacy BE. Overlap of functional dyspepsia and GERD-diagnostic and treatment implications. Nat Rev Gastroenterol Hepatol 2013;10:175-186.

46. von Wulffen M, Talley NJ, Hammer J, et al. Overlap of irritable bowel syndrome and functional dyspepsia in the clinical setting: prevalence and risk factors. Dig Dis Sci 2019;64:480-486.

47. Lee SW, Lee TY, Lien HC, Yeh HZ, Chang CS, Ko CW. The risk factors and quality of life in patients with overlapping functional dyspepsia or peptic ulcer disease with gastroesophageal reflux disease. Gut Liver 2014;8:160-164.

48. Yao X, Yang YS, Cui LH, et al. The overlap of upper functional gastro- 
intestinal disorders with irritable bowel syndrome in Chinese outpatients: a multicenter study. J Gastroenterol Hepatol 2016;31:1584-1593.

49. Kaji M, Fujiwara Y, Shiba M, et al. Prevalence of overlaps between GERD, FD and IBS and impact on health-related quality of life. J Gastroenterol Hepatol 2010;25:1151-1156.

50. Lei WY, Chang WC, Wen SH, et al. Impact of concomitant dyspepsia and irritable bowel syndrome on symptom burden in patients with gastroesophageal reflux disease. J Formos Med Assoc 2019;118:797-806.

51. Jarbøl DE, Rasmussen S, Balasubramaniam K, Elnegaard S, Haastrup PF. Self-rated health and functional capacity in individuals reporting overlapping symptoms of gastroesophageal reflux disease, functional dyspepsia and irritable bowel syndrome - a population based study. BMC Gastroenterol 2017;17:65.

52. Hantoro IF, Syam AF, Mudjaddid E, Setiati S, Abdullah M. Factors associated with health-related quality of life in patients with functional dyspepsia. Health Qual Life Outcomes 2018;16:83.

53. Lacy BE, Weiser KT, Kennedy AT, Crowell MD, Talley NJ. Functional dyspepsia: the economic impact to patients. Aliment Pharmacol Ther 2013;38:170-177.

54. Jones RH, Lydeard SE, Hobbs FD, et al. Dyspepsia in England and Scotland. Gut 1990;31:401-405.

55. Jones R, Lydeard S. Dyspepsia in the community: a follow-up study. Br J Clin Pract 1992;46:95-97.

56. Koloski NA, Talley NJ, Boyce PM. Predictors of health care seeking for irritable bowel syndrome and nonulcer dyspepsia: a critical review of the literature on symptom and psychosocial factors. Am J Gastroenterol 2001;96:1340-1349.

57. Ahlawat SK, Richard Locke G, Weaver AL, Farmer SA, Yawn BP, Talley NJ. Dyspepsia consulters and patterns of management: a populationbased study. Aliment Pharmacol Ther 2005;22:251-259.

58. Lee YY, Chua AS. What indigestion means to the Malays? J Neurogastroenterol Motil 2013;19:295-300.

59. Shinomiya T, Fukunaga M, Akamizu T, et al. Plasma acylated ghrelin levels correlate with subjective symptoms of functional dyspepsia in female patients. Scand J Gastroenterol 2005;40:648-653.

60. Mulak A, Taché Y, Larauche M. Sex hormones in the modulation of irritable bowel syndrome. World J Gastroenterol 2014;20:2433-2448.

61. Gill RC, Murphy PD, Hooper HR, Bowes KL, Kingma YJ. Effect of the menstrual cycle on gastric emptying. Digestion 1987;36:168-174.

62. Datz FL, Christian PE, Moore J. Gender-related differences in gastric emptying. J Nucl Med 1987;28:1204-1207.

63. Chen TS, Doong ML, Chang FY, Lee SD, Wang PS. Effects of sex steroid hormones on gastric emptying and gastrointestinal transit in rats. Am J Physiol 1995;268(1 Pt 1):G171-G176.

64. Meerveld BG, Johnson AC. Mechanisms of stress-induced visceral pain. J Neurogastroenterol Motil 2018;24:7-18.

65. Hellström B, Anderberg UM. Pain perception across the menstrual cycle phases in women with chronic pain. Percept Mot Skills 2003;96:201211.

66. Chaban V. Estrogen modulation of visceral nociceptors. Curr Trends Neurol 2013;7:51-55.

67. Houghton LA, Heitkemper M, Crowell M, et al. Age, gender and women's health and the patient. Gastroenterology 2016;150:1332-1343.

68. Kim YS, Kim N, Kim GH. Sex and gender differences in gastroesophageal reflux disease. J Neurogastroenterol Motil 2016;22:575-588.

69. Flier SN, Rose S. Is functional dyspepsia of particular concern in women? A review of gender differences in epidemiology, pathophysiologic mechanisms, clinical presentation, and management. Am J Gastroenterol 2006;101(12 suppl):644-653.

70. Dibaise JK, Islam RS, Dueck AC, Roarke MC, Crowell MD. Psychological distress in rome III functional dyspepsia patients presenting for testing of gastric emptying. Neurogastroenterol Motil 2016;28:196-205.

71. Mak AD, Wu JC, Chan Y, Chan FK, Sung JJ, Lee S. Dyspepsia is strongly associated with major depression and generalised anxiety disorder - a community study. Aliment Pharmacol Ther 2012;36:800-810.

72. Kindt S, Van Oudenhove L, Mispelon L, Caenepeel P, Arts J, Tack J. Longitudinal and cross-sectional factors associated with long-term clinical course in functional dyspepsia: a 5-year follow-up study. Am J Gastroenterol 2011;106:340-348.

73. Bangasser DA, Valentino RJ. Sex differences in molecular and cellular substrates of stress. Cell Mol Neurobiol 2012;32:709-723.

74. Zeng F, Sun R, He Z, et al. Altered functional connectivity of the amygdala and sex differences in functional dyspepsia. Clin Transl Gastroenterol 2019;10:e00046.

75. Lee IS, Wang H, Chae Y, Preissl H, Enck P. Functional neuroimaging studies in functional dyspepsia patients: a systematic review. Neurogastroenterol Motil 2016;28:793-805.

76. Zeng F, Qin W, Liang F, et al. Abnormal resting brain activity in patients with functional dyspepsia is related to symptom severity. Gastroenterol 2011;141:499-506

77. Zhou G, Qin W, Zeng F, et al. White-matter microstructural changes in functional dyspepsia: a diffusion tensor imaging study. Am J Gastroenterol 2013;108:260-269.

78. Vanheel H, Farré R. Changes in gastrointestinal tract function and structure in functional dyspepsia. Nat Rev Gastroenterol Hepatol 2013;10:142-149.

79. Vanheel H, Carbone F, Valvekens L, et al. Pathophysiological abnormalities in functional dyspepsia subgroups according to the rome III criteria. Am J Gastroenterol 2017;112:132-140.

80. Mori H, Suzuki H, Matsuzaki J, et al. Gender difference of gastric emptying in healthy volunteers and patients with functional dyspepsia. Digestion 2017;95:72-78.

81. Chial HJ, Camilleri C, Delgado-Aros S, et al. A nutrient drink test to assess maximum tolerated volume and postprandial symptoms: effects of gender, body mass index and age in health. Neurogastroenterol Motil 2002;14:249-253.

82. Boeckxstaens GE, Hirsch DP, van den Elzen BD, Heisterkamp SH, Tytgat GN. Impaired drinking capacity in patients with functional dyspepsia: relationship with proximal stomach function. Gastroenterol 2001;121:1054-1063.

83. Abid S, Anis MK, Azam Z, Jafri W, Lindberg G. Satiety drinking tests: effects of caloric content, drinking rate, gender, age, and body mass index. Scand J Gastroenterol 2009;44:551-556.

84. Mearadji B, Penning C, Vu MK, et al. Influence of gender on proximal 
gastric motor and sensory function. Am J Gastroenterol 2001;96:20662073.

85. Kojima M, Hosoda H, Date Y, Nakazato M, Matsuo H, Kangawa K. Ghrelin is a growth-hormone-releasing acylated peptide from stomach. Nature 1999;402:656-660.

86. van der Lely AJ, Tschöp M, Heiman ML, Ghigo E. Biological, physiological, pathophysiological, and pharmacological aspects of ghrelin. Endocr Rev 2004;25:426-457.

87. Ogiso K, Asakawa A, Amitani H, Inui A. Ghrelin: a gut hormonal basis of motility regulation and functional dyspepsia. J Gastroenterol Hepatol 2011;26(suppl 3):67-72.

88. Shindo T, Futagami S, Hiratsuka T, et al. Comparison of gastric emptying and plasma ghrelin levels in patients with functional dyspepsia and non-erosive reflux disease. Digestion 2009;79:65-72.

89. Choi YJ, Kim N, Yoon H, et al. Increase in plasma acyl ghrelin levels is associated with abatement of dyspepsia following Helicobacter pylori eradication. J Gastroenterol 2016;51:548-559.

90. Arisawa T, Tahara T, Shibata T, et al. Genetic polymorphisms of cyclooxygenase-1 (COX-1) are associated with functional dyspepsia in Japanese women. J Womens Health (Larchmt) 2008;17:1039-1043.

91. Du L, Kim JJ, Chen B, Zhang Y, Ren H. Gene polymorphisms and susceptibility to functional dyspepsia: a systematic review and metaanalysis. Gastroenterol Res Pract 2019;2019:3420548.

92. Triantafyllou K, Kourikou A, Gazouli M, Karamanolis GP, Dimitriadis GD. Functional dyspepsia susceptibility is related to CD14, GNB3, MIF, and TRPV1 gene polymorphisms in the Greek population. Neurogastroenterol Motil 2017;29:e12913.

93. Fukui H, Xu X, Miwa H. Role of gut microbiota-gut hormone axis in the pathophysiology of functional gastrointestinal disorders. J Neurogastroenterol Motil 2018;24:367-386.

94. Flak MB, Neves JF, Blumberg RS. Immunology. Welcome to the microgenderome. Science 2013;339:1044-1045.

95. Markle JG, Frank DN, Mortin-Toth S, et al. Sex differences in the gut microbiome drive hormone-dependent regulation of autoimmunity. Science 2013;339:1084-1088.

96. Santos-Marcos JA, Rangel-Zuñiga OA, Jimenez-Lucena R, et al. Influence of gender and menopausal status on gut microbiota. Maturitas 2018;116:43-53.

97. de la Cuesta-Zuluaga J, Kelley ST, Chen Y, et al. Age- and Sex-Dependent Patterns of Gut Microbial Diversity in Human Adults. mSystems 2019;4:e00261-19.

98. Shin JH, Park YH, Sim M, Kim SA, Joung H, Shin DM. Serum level of sex steroid hormone is associated with diversity and profiles of human gut microbiome. Res Microbiol 2019;170:192-201.

99. Kwa M, Plottel CS, Blaser MJ, Adams S. The intestinal microbiome and estrogen receptor-positive female breast cancer. J Natl Cancer Inst 2016;108.

100. Tan VP, Liu KS, Lam FY, Hung IF, Yuen MF, Leung WK. Randomised clinical trial: rifaximin versus placebo for the treatment of functional dyspepsia. Aliment Pharmacol Ther 2017;45:767-776.

101. Shin A, Preidis GA, Shulman R, Kashyap PC. The gut microbiome in adult and pediatric functional gastrointestinal disorders. Clin Gastroen- terol Hepatol 2019;17:256-274

102. Igarashi M, Nakae H, Matsuoka T, et al. Alteration in the gastric microbiota and its restoration by probiotics in patients with functional dyspepsia. BMJ Open Gastroenterol 2017;4:e000144.

103. Vanheel H, Vicario M, Vanuytsel T, et al. Impaired duodenal mucosal integrity and low-grade inflammation in functional dyspepsia. Gut 2014;63:262-271.

104. Komori K, Ihara E, Minoda Y, et al. The altered mucosal barrier function in the duodenum plays a role in the pathogenesis of functional dyspepsia. Dig Dis Sci 2019;64:3228-3239.

105. Zhuo Z, Zhang L, Ding M, et al. Estrogen decreases tight junction protein ZO-1 expression in human primary gut tissues. Clin Immunol 2017;183:174-180.

106. Zhou Z, Bian C, Luo Z, et al. Progesterone decreases gut permeability through upregulating occludin expression in primary human gut tissues and Caco-2 cells. Sci Rep 2019;9:8367.

107. Lee JY, Kim N, Choi YJ, et al. Expression of tight junction proteins according to functional dyspepsia subtype and sex. J Neurogastoenterol Motil 2020;26:248-258.

108. Duncanson KR, Talley NJ, Walker MM, Burrows TL. Food and functional dyspepsia: a systematic review. J Hum Nutr Diet 2018;31:390407.

109. Keshteli AH, Haghighatdoost F, Azadbakht L, et al. Dietary glycaemic index and glycaemic load and upper gastrointestinal disorders: results from the SEPAHAN study. J Hum Nutr Diet 2017;30:714-723.

110. Monrroy H, Borghi G, Pribic T, et al. Biological response to meal ingestion: gender differences. Nutrients 2019;11:E702.

111. Wang YP, Herndon CC, Lu CL. Non-pharmacological approach in the management of funcioanl dyspepsia. J Neurogastroenterol Motil 2019;26:6-15.

112. Islam MM, Iqbal U, Walther BA, et al. Gender-based personalized pharmacotherapy: a systematic review. Arch Gynecol Obstet 2017;295:1305-1317

113. Talley NJ. Functional dyspepsia: new insights into pathogenesis and therapy. Korean J Intern Med 2016;31:444-456.

114. Kim YJ, Chung WC, Kim BW, et al. Is Helicobacter pylori associated functional dyspepsia correlated with dysbiosis? J Neurogastroenterol Motil 2017;23:504-516.

115. Moayyedi PM, Lacy BE, Andrews CN, Enns RA, Howden CW, Vakil N. ACG and CAG clinical guideline: management of dyspepsia. Am J Gastroenterol 2017;112:988-1013.

116. Miwa H, Ghoshal UC, Fock KM, et al. Asian consensus report on functional dyspepsia. J Gastroenterol Hepatol 2012;27:626-641.

117. Kawakubo H, Tanaka Y, Tsuruoka N, et al. Upper gastrointestinal symptoms are more frequent in female than male young healthy Japanese volunteers as evaluated by questionnaire. J Neurogastroenterol Motil 2016;22:248-253.

118. Lorena SL, Tinois E, Brunetto SQ, Camargo EE, Mesquita MA. Gastric emptying and intragastric distribution of a solid meal in functional dyspepsia: influence of gender and anxiety. J Clin Gastroenterol 2004;38:230-236.

119. Winthorst WH, Post WJ, Meesters Y, Penninx BW, Nolen WA. 
Seasonality in depressive and anxiety symptoms among primary care patients and in patients with depressive and anxiety disorders; results from the Netherlands study of depression and anxiety. BMC Psychiatry 2011;11:198.

120. Shmuely H, Yahav J, Samra Z, Chodick G, Ofek I. Elevated 13C urea breath test values females infected with Helicobacter pylori. Dig Dis Sci 2007;52:402-404.

121. Moshkowitz M, Horowitz N, Beit-Or A, Halpern Z, Santo E. Gender-associated differences in urea breath test for Helicobacter pylori infection referrals and results among dyspeptic patients. World J Gastrointest Pathophysiol 2012;3:80-84.

122. Keers R, Aitchison KJ. Gender differences in antidepressant drug response. Int Rev Psychiatry 2010;22:485-500.

123. Parker G, Parker K, Austin MP, Mitchell P, Brotchie H. Gender differences in response to differing antidepressant drug classes: two negative studies. Psychol Med 2003;33:1473-1477.

124. Luo L, Du L, Shen J, Cen M, Dai N. Benefit of small dose antidepressants for functional dyspepsia: experience from a tertiary center in eastern China. Medicine (Baltimore) 2019;98:e17501.

125. Naito S, Sato K, Yoshida K, et al. Gender differences in the clinical effects of fluvoxamine and milnacipran in Japanese major depressive patients. Psychiatry Clin Neurosci 2007;61:421-427.

126. Kornstein SG, Schatzberg AF, Thase ME, et al. Gender differences in treatment response to sertraline versus imipramine in chronic depression. Am J Psychiatry 2000;157:1445-1452.

127. Khan A, Brodhead AE, Schwartz KA, Kolts RL, Brown WA. Sex differences in antidepressant response in recent antidepressant clinical trials. J Clin Psychopharmacol 2005;25:318-324.

128. Berlanga C, Flores-Ramos M. Different gender response to serotonergic and noradrenergic antidepressants. A comparative study of the efficacy of citalopram and reboxetine. J Affect Disord 2006;95:119-123.

129. Young EA, Kornstein SG, Marcus SM, et al. Sex differences in response to citalopram: a STAR*D report. J Psychiatr Res 2009;43:503511.

130. Zhong L, Shanahan ER, Raj A, et al. Dyspepsia and the microbiome: time to focus on the small intestine. Gut 2017;66:1168-1169.

131. Mirbagheri SS, Mirbagheri SA, Nabavizadeh B, et al. Impact of microscopic duodenitis on symptomatic response to Helicobacter pylori eradication in functional dyspepsia. Dig Dis Sci 2015;60:163-167.

132. Xu D, Gao J, Gillilland M 3rd, et al. Rifaximin alters intestinal bacteria and prevents stress-induced gut inflammation and visceral hyperalgesia in rats. Gastroenterol 2014;146:484-496, e4.

133. Ohtsu T, Takagi A, Uemura N, et al. The ameliorating effect of Lactobacillus gasseri OLL2716 on functional dyspepsia in Helicobacter pylori- Uninfected individuals: a randomized controlled study. Digestion 2017;96:92-102. 